\title{
LA NARRATIVA COSTARRICENSE DEL ÚLTIMO TERCIO DE SIGLO
}

Alvaro Quesada Soto Universidad de Costa Rica

\section{La "Segunda República"}

La década de 1960 marca el inicio de un renacer en la narrativa costarricense, relativamente estancada en los años 50 tras el florecimiento de los 40. Los narradores que comienzan a publicar en esta época pueden ser ubicados por su edad y formación ideológicoliteraria en diversos grupos, aunque en su producción y en sus actividades literarias interactúan y coinciden cronológicamente como si formaran una misma promoción.

Un primer grupo, cuyo período de formación coincide con los inicios del proyecto modernizador de la "Segunda República", que se inicia hacia 1950, estaría conformado por, entre otros, Alberto Cañas (1920), Julieta Pinto (1922), José León Sánchez (1929), Carmen Naranjo (1931), Rima de Vallbona (1931), Samuel Rovinski (1932), Virgilio Mora (1935). Un segundo grupo, cuyo período de formación coincide con las transformaciones ideológicas y culturales ligadas a la Revolución Cubana y las revueltas estudiantiles y juveniles de los años 60 y 70, estaría conformado por los narradores Fernando Durán Ayanegui (1939), Quince Duncan (1940), Alfonso Chase (1945), Gerardo César Hurtado (1949). A estos grupos cabría agregar el nombre de la escritora chilena Myriam Bustos (1933), quien reside y publica en Costa Rica desde 1976. 
Tras la guerra civil de 1948 se inicia en Costa Rica un nuevo proyecto nacionalista y un nuevo período modernizador - una "Segunda República”, según sus ideólogos, debía sustituir a la obsoleta República Liberal - siguiendo los parámetros del nuevo orden que se delineaba tras la II Guerra Mundial y el inicio de la "Guerra Fría”. En el ámbito interno, el período está dominado por la ideología socialdemócrata, encarnada en el Partido Liberación Nacional. Durante este período se afianza una nueva versión de la historia costarricense, elaborada por Rodrigo Facio y Carlos Monge en las décadas de 1930 y 1940. Según esta versión el predominio de pequeños propietarios campesinos generó, a lo largo de la historia nacional, un sedimento de igualdad y democracia amenazadas por el surgimiento de la oligarquía cafetalera, el liberalismo y el libre mercado, que llevaban a la desigualdad, el latifundio o el control de las empresas y países poderosos sobre la economía nacional. El nuevo proyecto histórico que se desprendía de esta visión del pasado tendía al control de la oligarquía cafetalera y al desmantelamiento de la República liberal oligárquica mediante la combinación de varios factores: la fundación de un partido ideológico con un nuevo proyecto modernizador; la organización de un Estado Nacional que orientara la marcha de la economía y regulara las relaciones sociales; la sustitución del monocultivo del café por una diversificación agrícola y el fomento de la industria ${ }^{1}$.

La visión de la historia costarricense se hacía coincidir, en forma coherente, con las teorías keynesianas y el "new deal" entonces en boga, para promover el surgimiento de un "Estado benefactor" y un proyecto de "sustitución de importaciones" que permitiera, a juicio de sus ideólogos, armonizar la modernización capitalista con la justicia

1. Los mejores expositores del proyecto son el propio Facio en su Estudio sobre economía costarricense (1940) y los artículos recopilados en el I tomo de sus Obras Completas (1975), y José Figueres en sus Cartas a un ciudadano (1956). La reconstrucción del contexto histórico se realiza con base principalmente en Iván Molina y Steven Palmer, Historia de Costa Rica (San José: Editorial de la Universidad de Costa Rica, 1997). 
swcial. En el plano ideológico, dentro del contexto de la "guerra fría", li socialdemocracia costarricense, aliada de los Estados Unidos y del hlocuc capitalista internacional, mantuvo una posición ambigua, de precur ias alianzas o enfrentamientos, con los grupos más conservadoI s ---ligados a la vieja oligarquía cafetalera y reunidos en agrupacioII''s como la ANFE o el periódico La Nación- y los grupos más r idlicales o revolucionarios, afines al comunismo o el socialismo.

A partir de 1948 se abolió el ejército, se perfeccionaron los mecanismos electorales, se nacionalizó la banca y se crearon o lurtalecieron una serie de instituciones públicas encargadas de la expansión, a lo largo del territorio nacional, de la educación, la salud y la cultura, de las carreteras y vías de comunicación, de los servicios cléctricos y telefónicos o del turismo; otra red de instituciones se cncargaba de arbitrar las relaciones entre propietarios y trabajadores () productores y consumidores. Las nuevas oportunidades educativas y sociales fortalecieron el crecimiento de una clase media y de una sociedad más democrática, menos estratificada, con mayores opciones de ascenso y movilidad social.

La promoción estatal en el ámbito de la educación y la cultura ${ }^{2}$, así como el papel de la recién fundada Universidad de Costa Rica, fueron fundamentales para el auge de la literatura y el teatro en estas décadas. Bajo el patrocinio de la Universidad de Costa Rica se fundó en 1952 un Teatro Universitario, se escribieron las primeras tesis y estudios académicos sobre literatura nacional, y se escribió la célebre Historia y antología de la literatura costarricense (1957-1961) — primera versión ordenada y sistemática de la historia literaria nacional- de Abelardo Bonilla. Hacia esta época los autores costarricenses se incluyen por primera vez en los programas escolares de literatura. En 1959 se funda la Editorial Costa Rica, ente estatal que jugó un papel inapreciable en

2. Para las políticas culturales en Costa Rica, véase Rafael Cuevas, El punto sobre la I. Políticas culturales en Costa Rica (1948-1990) (San José: Ministerio de Cultura, Juventud y Deportes, 1996). 
el rescate y difusión de obras del pasado, agotadas o casi inaccesibles, y en la promoción de nuevos autores: por primera vez la literatura costarricense estaba al alcance de todos los lectores, y los autores podían publicar sus textos sin tener que sufragar ellos mismos la edición. En 1970 se fundó el Ministerio de Cultura que ejerció un papel importante en la subvención y promoción del arte, el teatro y la literatura. Poco después se fundan la Universidad Nacional, la Universidad Estatal a Distancia y el Instituto Tecnológico de Costa Rica.

Sin embargo, tras esta fachada de modernización democrática, crecimiento y progreso, se experimentaban también nuevas formas de dominio, corrupción, y enajenación. El crecimiento del Estado bajo el nuevo proyecto nacionalista y modernizador llevaba al endeudamiento y la dependencia de los gobiernos extranjeros, organismos y empresas transnacionales, que financiaban o controlaban el proceso. El crecimiento del Estado llevaba a la consolidación de un aparato burocrático que se tornaba cada vez más omnímodo, autárquico e incontrolable. En evidente contraste con lo predicado por Facio y los ideólogos de la "Segunda República", el proyecto conducía a la sustitución de la vieja oligarquía cafetalera por una nueva oligarquía de políticos empresarios, burócratas y gerentes, ligados al nuevo proyecto modernizador; el dominio ejercido por el aparato burocrático y el Partido Liberación Nacional llevaba a nuevas formas de "argollismo" o clientelismo y, la incipiente "industrialización", más que a "sustituir importaciones" conducia a nuevas formas de endeudamiento y dependencia.

En el ámbito cultural la modernización, que generaba nuevas opciones sociales, culturales y educativas, se percibía también como generadora de descomposición social, enajenación, pérdida de valores e identidad. Por un lado, con las migraciones provocadas por el agotamiento de la frontera agrícola y el nuevo proyecto modernizador, se rompió definitivamente el tradicional equilibrio entre las culturas rural y urbana. A partir de 1950 se inicia un crecimiento canceroso, desordenado y ćaótico, de San José y el área metropolitana, debido 
tanto a la inmigración incontrolable como a una "modernización" equívoca, que destruyó el patrimonio arquitectónico, desfiguró el perfil de la ciudad y desparramó a los pobladores en barrios residenciales, urbanizaciones y tugurios, que proliferaron en forma caótica, descontrolada y aleatoria por los antiguos potreros y cafetales aledaños.

La educación rural y el alfabetismo que se masificaron a partir de 1950, al mismo tiempo que generaron nuevas opciones educativas para grupos sociales marginados, también fueron borrando poco a poco los últimos vestigios de las viejas culturas ligadas a la tradición oral y campesina, y alteraron radicalmente el perfil tradicional del "concho" o el "labriego sencillo", representación típica de la identidad nacional en la literatura costumbrista y la memoria colectiva del costarricense. A este proceso coadyuvó la creciente urbanización y la penetración - junto con las carreteras y la electricidad — de las nuevas culturas de masas o los nuevos patrones de consumo, ligados a la influencia dominante de la cultura estadounidense — que en estos años sustituye definitivamente a Europa como metrópolis cultural-y de medios de comunicación como el radio, el cine y — a partir de 1960la televisión.

Nuevos patrones culturales, asociados a las nuevas culturas de masas y a las clases medias y populares urbanas - cuyo estereotipo negativo sería la figura del "pachuco"- se difunden y ganan espacio en la ciudad, ante el desconcierto, la curiosidad o el disgusto de las viejas élites o los intelectuales, quienes veían modificarse vertiginosamente o desaparecer los rasgos físicos y culturales que habían caracterizado la fisonomía tradicional del país desde fines del siglo pasado. En las décadas de 1960 y 1970 las transformaciones ideológicas y culturales se agudizan con el auge, tras el triunfo de la Revolución Cubana, de las ideas "tercermundistas", anticolonialistas y antimperialistas, por una parte; y el impacto, por otra parte, hacia 1970, de las nuevas culturas "pop" o "contraculturas", los "hippies" y los "beatniks", las rebeliones estudiantiles y juveniles, con su radicalismo irreverente y su rechazo a la educación, la moral y el orden social tradicionales. 


\section{La promoción de 1960}

Gran parte de la producción narrativa de Alberto Cañas ${ }^{3}$ (de Una casa en el Barrio del Carmen, 1965, a Feliz año, Chávez Chávez, 1975, y Los molinos de Dios, 1992) y Julieta Pinto ${ }^{4}$ (Los marginados, 1970; El eco de los pasos, 1979; Tierra de espejismos, 1991) retoma la vertiente realista de denuncia o indagación social que había emprendido la "generación del 40", aunque poniendo énfasis en el análisis de las nuevas transformaciones en los grupos dirigentes y clases medias, en la vida urbana y el campo, que nacían con el nuevo proyecto modernizador; y con una posición ideológica más cercana a la socialdemocracia que al comunismo (mayoritariamente asumido por los novelistas de la "generación del 40"). Es frecuente en algunos de esos textos la rcflexión sobre el desarrollo histórico del país, mediante la introducción de personajes y situaciones que ponen en evidencia el contraste entre los ideales patrióticos, las prédicas de justicia y reforma social que guiaron las luchas del 48 y el nuevo orden que se había venido construyendo, caracterizado por la insensibilidad burocrática, el argollismo, la enajenación y el oportunismo. A esta misma temática se acercan algunas novelas de otros autores más jóvenes como Duncan (Final de calle, 1979) y Hurtado $^{5}$ (Los vencidos, 1977).

3. Cfr. Nirya Alan León, Feliz año, Chaves Chaves. La crisis de ideas políticas (tesis, San José: Universidad de Costa Rica, 1978) y José Eduardo Calderón Lamas, Lectura ideológica de "Felizaño, Chaves Chaves" (tesis, San José: Universidad de Costa Rica, 1983).

4. Vianney Carmona Obando y Fernando Guerrero Rojas, La evocación como estructura de la novela en "El Eco de los Pasos" de Julieta Pinto (tesis, San José: Universidad de Costa Rica, 1981); Luz Ivette Martínez, "Trayectoria vital de la obra de Carmen Naranjo”, Káñina, año 15, n. 1-2(1991) 47-53; Xinia Murillo Barrios, El rol femenino en "Los sucesos" de Julieta Pinto (tesis, Universidad de Costa Rica, 19920; José Manuel Fallas Porras, Dela esperanza a la desilusión en lasestructuras de la narrativa costarricense: enfoque histórico-social (1950-1985)(tesis de Maestría, Universidad de Costa Rica, 1997 ).

5. Rose Mary Hernández y Magda Brenes, Los vencidos y su afinidad con el discurso histórico (tesis, San Universidad de Costa Rica, 1978). 
Más cercano por su temática y su posición ideológica a la novela (k) 40, el relato testimonial autobiográfico de Luisa González, A ras del suelo (1970), narra el ascenso socio-cultural — mediante su ingresi) a la Escuela Normal - y la concienciación política - mediante su ingreso al Partido Comunista- de una mujer de origen proletario en cl San José del primer tercio del siglo XX. Las novelas de José L. Sínchez retoman también de la novela del 40 , la preocupación por Icstimoniar —desde el punto de vista de personajes marginalesámbitos periféricos de la historia o la vida social: el presidio de San I ucas en La isla de los hombres solos (1963), los enclaves mineros de Abangares en La colina del buey (1972).

Un fenómeno nuevo en la literatura costarricense de este período es la aparición de los primeros escritores afrocaribeños como Duncan () la poetisa Eulalia Bernard. En relatos y novelas de Duncan ${ }^{6}$ como Hombres curtidos (1973), Los cuatro espejos (1975), La paz del pucblo (1979), Kimbo (1989), la historia, la vida y la cultura afrocaribeñas o los problemas raciales, se enuncian por primera vez en la literatura costarricense desde el punto de vista de un escritor negro ${ }^{7}$.

Las transformaciones en la vida, los sujetos, discursos y culturas urbanas, la mentalidad burocrática, las nuevas variantes del poder, la enajenación y la incomunicación se exploran, recurriendo a complejas combinaciones discursivas o técnicas novedosas y experimentales, en Ceremonia de casta (1976) de Rovinski ${ }^{8}$ y, sobre todo, en la amplia,

6. María Eugenia Acosta Rodríguez, Lo estructural y lo psicológico en "Los cuatro espejos" y "Elnegroantillano: inmigracióny presencia" (tesis, Universidad de Costa Rica, 1984); Rocío Alvarez Velázquez y Nuria María Cordero Solís, “Los cuatro espejos" como un relato de identidad (tesis, San José: Universidad de Costa Rica, 1978); Edwin Salas Zamora, “La identidad cultural del negro en las novelas de Quince Duncan. Aspectos temáticos y técnicos”, Revista Iberoamericana, año 53, n. 138-139 (1987) 377-389; Donald K. Gordon, Lo jamaicano y lo universal en la obra del costarricense Quince Duncan (San José: Editorial Costa Rica, 1989).

7. Duncan es también el editor de un estudio antológico sobre El negro en la literatura costarricense (1975.).

8. A. C. Araya María Elena del Vecchio, Tradición/no tradición: el paradigma fundamental en la novela "Ceremonia de casta" (tesis, Universidad de Costa Rica, 1978); María Elena Carballo, "Padre e hijo en Ceremonia de casta. El mundo de la bastardía". 
innovadora y rica producción narrativa de Carmen Naranjo ${ }^{9}$, donde sobresalen las novelas Los perros no ladraron (1966), Camino al mediodía (1968), Memorias de un hombre palabra (1968), Responso por el niño Juan Manuel (1971), Diario de una multitud (1974), amén de numerosos cuentarios. La imagen de la ciudad que ofrecen los textos de Naranjo es la de un mundo gris y hostil, impersonal o anónimo; la mediocridad y la trivialidad, la ausencia de personalidad y autoestima, la incomunicación y el aislamiento, o un malestar y un miedo indefinibles, corroen la subjetividad de los habitantes. Los personajes, en el sentido tradicional del término, son frecuentemente sustituidos por voces errantes, sin cuerpo y sin alma, que deambulan por un mundo urbano sin centro, sin orden, ni coherencia, ni sentido. Las novelas de Virgilio Mora ${ }^{10}$, con procedimientos narrativos innovadores y

Revista Iberoamericana, año 53, n. 138-139 (1987) 435; Leda María Díaz, "Social democracia y clase media en Ceremonia de casta y Diario de una multitud", Káñina, año 11, n. 2 (1987) 41-46.

9. María Elena Carballo Castegnaro y Sonia Marta Mora E., El discurso literario en "Responso por el niño Juan Manuel" y "Diario de una multitud" (Análisis estructural)(tesis, Universidad de Costa Rica, 1976); María Amoretti, “Caminoalmedio día”, Revista de Filologíay Lingüística de la Universidad de Costa Rica, año 5, n.1-2(1979) 55-59; Alicia Miranda Hevia, Novela, discurso y sociedad. "Diario de una multitud", (San José: Mesén Editores, 1985); Luz Ivette Martínez, Carmen Naranjoy la narrativa femenina en Costa Rica, (San José: Editorial Universitaria Centroamericana, 1987); María Eugenia Acuña, "Bibliografía comentada de Carmen Naranjo", Letras n.22 (1989), número completo; Seidy Araya Solano, "La enajenación de la mujer en los sectores medios: 'Los perros no ladraron' de Carmen Naranjo”, Káñina, año 15, n.12 (1991) 55-65; Flor Garita Hernández, "La visión estereoscópica en la novela 'Responso por el niño Juan Manuel', Káñina, año 18, n. 2 (1994) 9-18.

10. Julieta Fonseca Peñaranda, "Cachaza" relato novedoso en la literatura costarricense (tesis, Universidad de Costa Rica, 1979); María Amoretti, “'Cachaza': el relajo del carnaval y el diálogo de los contrarios”, Káñina, año 7, n. 12 (1983) 21-32, Introducción al socio-texto. A propósito de "Cachaza" (San José: Editorial de la Universidad de Costa Rica, 1989), "El odioso de Mora", Revista de Filología y Lingüística de la Universidad de Costa Rica, año 21, n. 2(1995) 7-16; Ruth Cubillo y Franklin Herrera, “'Cachaza': una visión de lo siniestro”, en Víctor Sánchez (comp.) Memoria del IV Congreso Costarricense de Filología, Lingiuística y Literatura (Universidad de Costa Rica, 1993) 175-179; Ivonne Robles Mohs, “La película: una cornucopia neobarroca”, Revista de Filología y Lingüística de la Universidad de Costa Rica, año 24, n. 2 (1998) $25-42$. 
una agresividad verbal inusitada en la literatura costarricense, exploran también fenómenos de marginación urbana, ligados a la locura, el sadomasoquismo, la represión social, síquica y sexual, en varios relatos y novelas que se inician con Cachaza (1977).

La incorporación de áreas de la vida social censuradas en el discurso literario tradicional (el ámbito de la vida sexual, lo escatológico e indecente, el mundo de la prostitución o el alcoholismo, lo que por decencia no se dice ni escribe públicamente) o la apropiación de los nuevos discursos urbanos del "pachuco" o el lumpen marginal, comienza a aparecer en textos de Mora (Cachaza, La película, La loca Prado, Los problemas del gato, los cuentos reunidos en La distancia del último adiós), en algunos cuentos de Chase incluidos en Mirar con inocencia (1975) y Ella usaba bikini (1991), o en la serie de relatos testimoniales, de escasa pretensión literaria pero de gran difusión en la década de 1970, de Alfredo Oreamuno Sinatra.

En concordancia con el nuevo papel que la mujer comienza a jugar en la sociedad a partir de 1949, al ser incorporada como ciudadana plena con derecho a voto, aumenta sustancialmente la presencia femenina en la literatura costarricense contemporánea. Las figuras femeninas, excepcionales en la literatura de los dos primeros tercios del siglo, ingresan masivamente a la literatura en el último tercio. Una parte de la producción narrativa de estas décadas se preocupa por explorar los temas de la vida familiar, la discriminación sexista o las relaciones de género, desde la óptica de la mujer y la percepción femenina, en varias novelas y relatos de Pinto (Si se oyera el silencio, 1967; La estación que sigue al verano, 1969), Vallbona ${ }^{11}$

11. Julia María Conejo Guevara, "Noche en vela” (nivel de las acciones) (tesis, Universidad de Costa Rica, 1976); Cida S. Chase, "El mundo femenino en algunos cuentos de Rima de Vallbona", Revista Iberoamericana, 53, 138-139 (1987) 403-417; M. López, "Directrices temáticas en tres cuentos de Rima de Valbona", Revista de Filología y Lingüística de la Universidad de Costa Rica, 24, 1 (1988) 67-72; Ofelia Durán Cubillo, "Rasgos del relato moderno en el orden temporal de Noche en vela", Káñina, año 16, n. 2 (1992) 9-16; Virginia Caamaño Morúa, Mujeres en el laberinto: la construcción de las figuras femeninas en tres cuentos de Rima de Vallbona (tesis de Maestría, Universidad de Costa Rica, 1997). 
(Noche en vela, 1968), Naranjo (Sobrepunto, 1985) y en numerosos relatos de Bustos ${ }^{12}$.

Entre el grupo de autores más jóvenes que se forman bajo el influjo de las revueltas juveniles y estudiantiles, en las novelas (Los juegos furtivos, 1968, Las puertas de la noche, 1974) y algunos cuentos de Chase, en las novelas de Hurtado ${ }^{13} *$ (Irazú, 1972, Los $^{2}$ parques, Así en la vida como en la muerte, 1975; Libro brujo, 1998), o en la novela El pasado es un extraño país (1993) de Daniel Gallegos $^{14}$, es frecuente el tema del joven o el adolescente en búsqueda problemática de su identidad en un mundo cuyas normas y valores se perciben como extraños u hostiles a la subjetividad de los protagonistas. Predomina en estas novelas la temática — por otra parte frecuente en toda la literatura de la época- de la soledad, el desarraigo, la incomunicación, el rechazo al orden social o los valores de los padres y ancestros, de los que se sienten exiliados o ajenos los jóvenes protagonistas.

Otra línea narrativa de esta época, que desarrolla una temática poco frecuentada por la literatura costarricense anterior, es la literatura fantástica o la literatura de intención lúdica, que juega —mediante recursos como el desdoblamiento, la intertextualidad, la ironía, la sátira o la parodia - con las convenciones que determinan los límites entre la realidad y la ficción, entre diversos géneros y discursos, entre uno y los otros, el tiempo y el espacio, lo serio o trascendental y lo cómico o intrascendente, en numerosos relatos de Durán ${ }^{15}$, Bustos,

12. María Inés Zaldívar, “Reiterándome” o la 'elevación' frente a la negación (San José: Editorial de la Universidad Nacional a Distancia, 1995).

13. Nory Molina, "Apuntes sobre una nueva narrativa costarricense: Gerardo César Hurtado”, Revista Iberoamericana, año 53, n. 138-139 (1987) 475-485; Miriam Jiménez C., “'El libro brujo' y la novela contemporánea”, Tópicos del Humanismo, n. 51 (1999).

14. Flora Ovares, "El desgarramiento del exilio" ("El pasado es un extraño país") La Nación, Suplemento Ancora (2 de abril 1995).

15. Amalia Chaverri, "Relaciones intertitulares a partir de Retorno al Kilimanjaro", Revista de Filología y Lingüística de la Universidad de Costa Rica, año 17, n.1-2 (1991) 21-27y “Asalto al paraíso". Una transmetáforaque reescribe la historia (tesis 
algunos textos de Chase, El despertar de Lázaro (1994) de Pinto, las últimas novelas de Mora como Mano a mano, o la novela póstuma de Mario Picado Lino XIX.

En toda la narrativa de esta época se tornan más complejas y problemáticas las relaciones entre subjetividad y orden social, una característica que se había venido agudizando a lo largo de la historia literaria costarricense. Las relaciones de dominación o enajenación, se manifiestan cada vez más difíciles de determinar y representar pues pasan, de identificarse con figuras o instituciones fácilmente ubicables en el mundo objetivo — como el Estado, el mercado, el latifundio, las bananeras-, a identificarse con estructuras más difíciles de percibir conscientemente, pero igualmente represivas y omnímodas - como el patriarcalismo, la burocracia o los sistemas de control ideológicoque tienden a trasladar los conflictos desde la realidad objetiva a la subjetividad misma del personaje ${ }^{16}$. La relación más compleja entre subjetividad y orden social torna también más compleja la representación de la realidad mediante la escritura: los límites tienden a disolverse en abigarrados juegos discursivos donde es difícil reconocer las fronteras entre lo "propio" y lo "ajeno", lo subjetivo y lo objetivo, lo real y lo imaginario.

La mayor parte de estos autores, cuyos textos coinciden con la difusión del llamado "boom" de la nueva narrativa latinoamericana, o la nueva crítica estructuralista, se caracterizan por la búsqueda de procedimientos innovadores o experimentales de escritura. Es característico de esta promoción, los cortes y montajes espacio-temporales que transmiten la imagen de una realidad fragmentada, múltiple o

de Maestría, Universidad de Costa Rica, 1997); Keri Meyers, "The Kilimanjaro kaleidoscope: a sociocritical approach to 'Retorno al Kilimanjaro", Revista de Filología y Lingüística de la Universidad de Costa Rica, año 17, n. 1-2 (1991) 29-38; Claudio Bogantes-Zamora, Lo fantástico y el doble en tres cuentos de DuránAyanegui (San José: Editorial de la Universidad de Costa Rica, 1999).

16. Margarita Rojas y Flora Ovares, 100 años de literatura costarricense (San José: Farben-Norma, 1995) y "Peregrinos y errabundos. La narrativa costarricense contemporánea”, Tópicos del Humanismo (Universidad Nacional) n. 29 (1998). 
heterogénea, imposible de aprehender como una unidad o totalidad organizada y coherente. A esto mismo coadyuva la experimentación con los discursos que traducen la expresión "en bruto" (no pulida o codificada) de la vivencia subjetiva, ya sea mediante el monólogo interior o la asociación más o menos libre de recuerdos, ocurrencias, palabras, sensaciones e imágenes.

\section{Globalización y posmodernidad}

La década de 1980 marca el ingreso de una nueva promoción de narradores donde figuran, entre otros, Linda Berrón (1951), Ana Cristina Rossi (1952), Hugo Rivas(1954-1992), Rodolfo Arias(1956), José Ricardo Chaves (1958), Dorelia Barahona (1959), Carlos Cortés (1962), Rodrigo Soto (1962), Fernando Contreras (1963). A esa lista se pueden agregar dos autores que por sus fechas de nacimiento deberían ser ubicados dentro de la promoción anterior, pero que por las fechas de publicación y las características de sus textos se acercan a esta última: Tatiana Lobo (1939) y Rafael Angel Herra (1943).

Las últimas décadas del siglo XX gestaron en Costa Rica, como en todo el planeta, cambios radicales y vertiginosos en todos los ámbitos; cambios que revolucionaron las formas consabidas de imaginarse a sí mismo, como sujeto o como ciudadano, y de situarse en la sociedad o el mundo.

En el ámbito político centroamericano la década de 1980 llevó, en sus inicios, a un agudizamiento de los conflictos enmarcados en la "guerra fría" y al auge de procesos revolucionarios en Nicaragua, El Salvador y Guatemala; más tarde, al terminar la década, esos procesos se revierten hacia un paulatino decaer de las ideologías políticas revolucionarias, tras el derrumbe del llamado "socialismo real" en la Unión Soviética y los países de Europa Oriental, y tras las luchas internas, divisiones y fragmentaciones de los partidos comunistas o socialistas. Se anuncia entonces el fin de la "guerra fría" y, según algunos, el "fin de la historia", el "fin de las utopías". Según esas 
apreciaciones se iniciaba un proceso de "globalización” que diluía las fronteras racionales y unificaba, bajo el signo ideológico del neoliberalismo, a un mundo organizado por el poder del capital transnacional como un único mercado global.

Ese proceso político coincidió con la crisis económica que estalló con fuerza hacia 1980. Los efectos de la crisis fueron especialmente fuertes y duraderos en toda América Latina y el llamado "Tercer Mundo". La imposibil'ıdad para los países pobres de pagar, en las nuevas condiciones, la deuda externa contraída en la época de auge de las finanzas mundiales, fue utilizada por las metrópolis acreedoras para trasladar a los países deudores los efertos de la crisis y de paso - aprovechando el desconcierto político--desarticular los movimientos "tercermundistas". Bajo la nueva idecilogía neoliberal dominante, se impuso una serie de "ajustes estructurales" que en gran medida condicionaban la sobrevivencia económica de los países pobres a ceder en sus pretensiones de soberanía nacional, y adoptar esquemas elaborados en las metrópolis e impuestos por organismos financieros internacionales. En términos generales, el proyecto globalizador constreñía a esos países, como única forma de sobrevivencia, a convertirse en terrenos abiertos a la especulación, el tráfago de capitales y el lavado de dinero; en consumidores de productos importados, y en suplidores de mano de obra barata y sumisa para el mercado internacional, o sus intermediarios criollos, una nueva oligarquía "globalizada" de empresarios, políticos y tecnócratas. Entre las principales consecuencias del "ajuste" se señala el logro de una cierta estabilidad macroeconómica a un precio social muy alto: la marginación o el empobrecimiento de las grandes mayorías y el decaimiento en los servicios públicos, contrasta con el surgimiento de una nueva oligarquía, una poderosa y rica élite políticoempresarial.

Más allá del ámbito de los discursos político y ecc nómico, el concepto de "globalización" se encuentra también asociadc al vertiginoso desarrollo de la tecnología, la informática y la comunı zación en los decenios finales del siglo. Las nuevas tecnologías, la informática 
o el impacto de las nuevas culturas de masas contribuyeron, junto con la globalización económica y política, a modificar los criterios establecidos de imaginar o simbolizar la realidad y a trastocar una de las formas tradicionales - ligada al Estado, la Nación o la cultura vernácula - de construirse como sujeto, de procurarse una identidad y definirse en relación consigo mismo, la sociedad y el mundo.

Basados en las ingentes transformaciones del período, pensadores e ideólogos de diversas tendencias proclamaron el fin de una época histórica y el inicio de una nueva era: la Posmodernidad. La Posmodernidad pondría en duda los presupuestos básicos de la Modernidad, que pasarían a ser simples "relatos"17 o convenciones, aceptables no por su valor de "verdad", sino por su funcionalidad o efectividad pragmáticas para imponer el control de la ley, el orden y la razón, sobre el deseo, la heterogeneidad y el azar. Por otra parte, diversos planteamientos desde variadas desciplinas, habían venido poniendo en duda las divisiones convencionales entre lo real, lo imaginario y lo simbólico, entre lenguaje o representación y realidad, entre objetividad y subjetividad, al estudiar problemas complejos como las mediaciones del poder o el inconsciente en la construcción de la subjetividad y la alteridad, o la mediación de los lenguajes, signos e ideologías, las prácticas discursivas o culturales, en la forma como los sujetos construyen su propia imagen y la imagen del mundo en que viven, $o$ sus patrones de comportamiento e interacción. Bajo el influjo de esas teorías y el decaimiento del marxismo o el socialismo ortodoxos, las reflexiones críticas o contestatarias en las humanidades se desplazan en este fin de siglo, del análisis de las estructuras sociales o las ideologías políticas, hacia el ámbito de las prácticas culturales y discursivas, la ecología, el sicoanálisis, los estudios de género y los derechos de las minorías culturales o sexuales.

En el ámbito costarricense, en las dos últimas décadas del siglo XX, los fenómenos ligados a la "globalización" o la "posmodernidad"

17. Jean François Lyotard, La condition postmoderne (Paris: Minuit, 1979). 
replantearon desde nuevas perspectivas viejos problemas, ya crínicos, asociados con los diversos proyectos "modernizadorcs" il liberal o el socialdemócrata - a lo largo del siglo: la enajenación, cl aumento excesivo del aparato estatal y la burocracia, el endeudamicnto, el crecimiento macrocéfalo y canceroso del área metropolitana, las migraciones internas y externas, la contaminación o destrucción del ambiente, la penetración inasimilable de una cultura de masas cada vez más omnipresente, el decaimiento de la solidaridad o el diálogo y el incremento, junto con la cultura de la competencia y del mercado, de un individualismo autárquico, la agresividad y la violencia.

La crisis de 1980 o, más tarde, los movimientos revolucionarios y las estrategias contrarrevolucionarias en Centroamérica, hicieron oscilar el país - en medio de una histeria protofascista- entre la paz o la guerra; entre la "neutralidad" y la soberanía, o la intervención económica y política y la ocupación militar solapada. Esos hechos, así como los fenómenos ligados a la "globalización", han generado, en las dos últimas décadas del siglo $\mathrm{XX}$, una metamorfosis radical —cuyo resultado es aun incierto- de la Nación y del Estado costarricenses que se habían venido construyendo a lo largo del último siglo, y han quebrado irreversiblemente la imagen que los costarricenses se habían forjado de su relación, como sujetos o ciudadanos, con su país o de su país con el mundo. Por otra parte, los discursos ligados a las posiciones "posmodernas" permitieron también plantear, desde una posición distanciada, desencantada o transgresora, la reivindicación de las culturas marginales y contraculturas, la revisión crítica de los mitos y construcciones ideológicas o culturales que sirvieron de base a los estereotipos y comportamientos difundidos por el nacionalismo y la cultura oficiales a lo largo del siglo XX.

En estas décadas se inicia bajo el dominio del neoliberalismo, aunque con ingentes resistencias desde otros ámbitos, un nuevo proyecto modernizador que en gran medida invierte los términos del proyecto propuesto por los ideólogos de la "Segunda República". En la nueva versión neoliberal de la historia costarricense, el papel de 
héroe recae sobre la empresa privada, a la que se asocian las nociones de libertad, riqueza, progreso y eficiencia; el papel de antihéroe pasa a ser desempeñado por el Estado benefactor, al que se le atribuyen las nociones opuestas: monopolio y corrupción, endeudamiento, demagogia, burocracia, ineficiencia. Un nuevo discurso oficial — difundido por el periódico La Nación, las cámaras de empresarios, instituciones públicas o las leyes sociales y laborales creadas políticos y conomistas neoliberales, y una serie de instituciones (CINDE, INCAE, Academia de Centroamérica, etc.) fundadas y financiadas por la AID estadounidense - procura identificar los intereses "nacionales" con los intereses de la nueva oligarquía globalizada de empresarios y políticos formada al amparo del "ajuste estructural". En el nuevo discurso se exige como imperativo histórico necesario para superar la crisis, "modernizarse" y sobrevivir en el nuevo mundo global, "sacrificios" a los trabajadores e "incentivos" para los empresarios; mientras por otra parte la venta del país - instituciones, patrimonio, tierras, trabajo - en el mercado internacional, pasa a confundirse con el "patriotismo". Los que se resisten a esas formas de globalización son definidos como "grupos de presión" o "antipatriotas" que defienden el "statu quo" (las bajo el Estado benefactor) y representan intereses locales o gremiales (los de organizaciones obreras y populares), opuestos a los intereses "nacionales" o "patrióticos", al "cambio", la "modernización” y el "progreso", postulados por la élite oligárquica.

La resistencia popular a los términos y consecuencias del "ajuste" es interpretada por la élite en el poder como un problema de "ingobernabilidad", lo que legitima la toma de decisiones inconsultas o arbitrarias, el engaño y el autoritarismo, disfrazados bajo lemas de “consenso" o "concertación". Los nexos y ramificaciones de la oligarquía entre las cúpulas de los dos partidos políticos oficiales (PUSCPLN), o el control que ejercen los miembros de la élite sobre los principales medios de información y propaganda — de los que son dueños o socios - les garantiza prácticamente el monopolio del poder político e ideológico, sin que se alteren sin embargo las apariencias 
formales de una democracia electoral. A eso se agrega un uso crecicinte del doble discurso por parte de la elite política: lo que se dice o promele es un ocultamiento constante de lo que se hace y practica.

La tensión entre los esfuerzos de la elite neoliberal por implantar su proyecto modernizador y las resistencias de las mayorías oprimidas por el “ajuste”, va generando una pugna cada vez más marcada y aguda en el interior del país: Costa Rica tiende a dividirse en dos mundos superpuestos, coexistentes pero radicalmente distintos. Un espacio "privado" - el que privilegia la imagen oficial de la Nación- que ofrece bienes y servicios de calidad a un alto precio, solo accesible a la elite, la clase media alta y el turismo extranjero; contrasta con un amplio espacio - semioculto en el discurso oficial- donde los salarios insuficientes, las condiciones de trabajo insatisfactorias, el deterioro o la eliminación de las instituciones y servicios públicos, un sistema impositivo que grava salarios y pensiones pero no grava las ganancias y fomenta la evasión y la corrupción, van delineando un mundo de excluidos o segregados, que ven decrecer su poder adquisitivo, sus esperanzas de mejoramiento y hasta sus posibilidades de sobrevivencia, mientras contemplan con estupor, con desesperación o con asco, la prosperidad, la corrupción y la impunidad de la elite. La visión crítica - que en ocasiones asume un humor corrosivo y una deconstrucción satírica o paródica de los estereotipos y discursos oficiales-y el desencanto ${ }^{18}$, son la tónica dominante en la literatura de los autores que se inician a partir de 1980, característica que asumen también textos de autores de la promoción anterior que se publican en estos años.

18. Una excelente y variada muestra de las reacciones de escritores e intelectuales ante cl "nuevo orden" que se construye en el país se puede encontrar en Alexander Jimúncz. y Jesús Oyamburu (comp.) Costa Rica imaginaria (Heredia: Editorial. Fundación Universidad Nacional, 1998). 


\section{La promoción del 80}

La crisis de 1980 y las vertiginosas transformaciones históricas y culturales reseñadas anteriormente, unidas al interés por la revisión de la historia que despertó la conmemoración del $\mathrm{V}$ centenario del "descubrimiento" de América, generaron en Costa Rica —al igual que en el resto de Hispanoamérica- una extraordinaria proliferación de la novela y el drama históricos. Este interés convoca tanto a autores que se habían ya iniciado en los 60, como Cañas, Sánchez ${ }^{19}$, Ayanegui $^{20}$, Chase ${ }^{21}$ o el dramaturgo Daniel Gallegos, como a debutantes. La nueva novela histórica costarricense - como su homóloga latinoamericana $^{22}$ - se preocupa por ofrecer una reinterpretación crítica de la historia oficial recurriendo a épocas y a procedimientos narrativos muy diversos, desde el realismo tradicional hasta recursos innovadores que combinan el dato histórico y el elemento fantástico; que introducen mitos, creencias y leyendas populares; que recogen la visión de las culturas indígenas, afrocaribeñas o marginales; que juegan - por medio de anacronismos, mezclas discursivas o reversiones paródicas - con la desacralización de los mitos y discursos oficiales.

Los molinos de Dios (1992) de Cañas —la más tradicional de estas novelas - ofrece una saga épica de los cafetaleros desde una visión de la historia cercana a la de Facio y Monge. Tenochtitlan (1986) de Sánchez of rece una narración de la conquista de México que

19. José Angel Vargas Vargas y Magdalena Vásquez Vargas, “'Tenochtitlán': una nueva dimensión de la historia”, Káñina, año 14, n.2 (1990): 51-57; Sonia Marta Mora, “La palabra ante el espejo. La novela costarricense de la década del 80" (mimeo); Arnoldo Mora Rodríguez, "La novelística femenina reciente en Costa Rica", Káñina, año 17, n.2(1993)7-20; Magda Lorena Alvarado Chávez, Marina enlanovela "Tenochtitlan". Una historia de temor y amor ( tesis de Maestría, Universidad de Costa Rica, 1998).

20. Alvaro Quesada Soto, "La estirpe de la enajenación", Herencia, año 1, n. 6 (1994).

21. Alfonso Chase, "Viaje metafórico a la historia" (entrevista) La Nación, Suplemento Ancora (1996) 27-10.

22. Seymour Menton, La nueva novela histórica de América Latina (México: Fondo de Cultura Económica, 1993). 
recupera el punto de vista y la percepción de los aztecas; Campanas para llamar al viento (1987), del mismo autor, explora la colonización española de California. El pavo real y la mariposa (1996) de Chase desmitifica la visión idealizada y arcádica de la época liberal, recuperando las tensiones y enfrentamientos que cruzaban la vida doméstica, cultural y política del período. Las estirpes de Montánchez (1992) de Durán Ayanegui es un texto complejo que desarrolla dos historias paralelas, con personajes que se desdoblan y cambian de identidad, saltos espacio-temporales, anacronismos y una mistificación constante de fechas y datos históricos, para ofrecer la imagen de un país latinoamericano cuya historia está marcada por la enajenación, el enmascaramiento de las identidades y el hundimiento en una violencia autodestructora. En El pasado es un extraño país (1993) de Gallegos, el proceso de formación de una conciencia en los marcos de una familia conflictiva, se asocia con la memoria histórica sobre la época de los Tinoco y con un proceso de desencanto y progresivo distanciamiento del protagonista hacia el desarrollo histórico y la modernización del país.

Descuella en el campo de la narrativa histórica la escritora Tatiana Lobo ${ }^{23}$, quien sorprendió con una primera novela excepcional: Asalto al paraíso (1992). La novela, que tiene como fondo la sublevación indígena de Presbere en 1709, rompe con la visión idealizada y bucólica de la Colonia que proclamaba la historia oficial. Cartago y Talamanca, el Valle Central y el Caribe se convierten, mediante una innovadora utilización del tópico del viaje iniciático y la transgresión de fronteras, en representación simbólica del encuentro entre diversas opciones culturales y vitales —el principio masculino

23. Ligia Bolaños, “'Asalto al paraíso': ¿asalto a la oficialidad?”, en Y. Solano (comp.) Memoria V Congresode Filología y Lingüística (San José: Guayacán, 1.994, 115-126); Tatiana Lobo, "Escribir no es vivir... pero se le parece”, La República, 1994; Amalia Chaverri Fonseca, “Ciudades en la literatura: en 'Calipso' y 'Viaje al reino de los deseos'”, en Saray Córdoba (ed.), La ciudad y sus historias (San José: Editorial de la Universidad de Costa Rica, 1999) 83-98. 
y racional o el principio femenino y pulsional; la razón occidental o la vivencia mítica aborigen - que dialogan en la conciencia del protagonista Pedro Albarán. Su segunda novela Calypso (1996) explora también los alcances del diálogo interétnico e intercultural, a través de varias generaciones de dos núcleos familiares - uno de un blanco, otro de un negro - en un pueblo costero del Caribe; personajes y pueblo se van formando y transformando en contacto con el ingreso de la "civilización" y los vertiginosos cambios históricos de la segunda mitad del siglo $\mathrm{XX}$.

Gran parte de la producción narrativa de fin de siglo se construye como reacción crítica a los procesos de desintegración social, descomposición moral y corrupción generalizada que se dan en el país a partir de 1980. Diversos aspectos, como las estrategias revolucionarias o contrarrevolucionarias, la venta o la entrega del país, la corrupción y la hipocresía políticas, el periodismo venal, el lavado de dinero y el narcotráfico, la marginación cultural y social, la destrucción ecológica, el contraste entre las apariencias que se muestran y la realidad que se oculta o se niega, son tratados desde diversas ópticas ideológicas y diversos procedimientos narrativos en una amplia gama de textos. Un grupo, más cercano al realismo social, al testimonio o la denuncia, está conformado por novelas como La luna de la hierba roja (1984) de Sánchez, Los sonidos de la aurora (1991) de Carlos Morales, La loca de Gandoca (1992) de Rossi, Retrato de mujer en terraza (1995) de Barahona.

Otro grupo recurre a procedimientos narrativos como la deformación carnavalesca, las inversiones o reversiones paródicas, las metamorfosis y desdoblamientos, el humor grotesco y el esperpento, para ofrecer la imagen de un mundo dislocado, en deterioro y descomposición, donde las fantasías o las apariencias — que remiten a las representaciones oficiales de un país excepcional o de un pasado venerable - se contraponen a un mundo anómalo y deforme, clandestino o marginal, regido por la exclusión, la represión y la violencia, el trastrueque de identidades y la enajenación. 
Mundicia (1992), "farsa épica" de Soto —cuyo título remite a la asociación inmundicia/tiquicia - rebaja y revierte en forma paródica y grotesca los estereotipos oficiales que privilegian la "excepcionalidad" del país. En Única mirando al mar (1993) de Contreras ${ }^{24}$, el basurero de Río Azul se convierte en símbolo de un país que excluye como basura desechable objetos de consumo y seres humanos. La humanidad y solidaridad de los "buzos" que viven en el basurero, contrasta con la inhumanidad y destructividad del mundo que los margina: los sujetos "normales" que viven bajo las normas de la “civilización”, la “modernidad” y el “progreso". En Los Peor (1995), segunda novela de Contreras, una antigua casa, convertida ahora en prostíbulo, esconde en sus cimientos las reliquias olvidadas y ocultas de la gesta heroica de 1856. El personaje central es un cíclope; producto de mutaciones debidas al uso de agroquímicos, y la imagen de la ciudad se construye mediante la superposición de tiempos históricos y culturales. El mundo moderno — un San José esperpéntico y contaminado, habitado por "chapulines"- se mezcla con referencias mitológicas, clásicas, medievales o renacentistas y con la imagen - que solo los ciegos o locos ven-del mítico San José de la época liberal, anterior al proyecto modernizador de la "Segunda República". Cruz de olvido (1999) de Cortés ${ }^{25}$, toma como protagonista un revolucionario desengañado y construye también la imagen de un San

24. Karlissa Cavallini y Carlos Morales, "Fernando Contreras: constructor y soñador entre mareas malolientes", Universidad (26 de noviembre 1993); Amalia Chaverri, "Unica mirando al mar (la basura se recicla en la literatura), La Nación. Suplemento Ancora (18 de octubre 1993); Rodolfo Cardona Cooper, "Balance esperpéntico. 'Los peor' de Fernando Contreras", La Nación, Suplemento Ancora (17 de marzo 1996); Fernando Contreras Castro, "Un peor hace cien", La Nación, Suplemento Ancora (17 de marzo 1996); Leda María Díaz, "Única mirando al mar: una proliferación del sentido", Káñina, año 19, n.2 (1995) 9-14.

25. Amalia Chaverri, “'Cruz de Olvido'. La (in)fidelidad de la ficción”, La Nación. Suplemento Ancora (27 de junio 1999); Manuel Bermúdez, "Esta cruz es mi reconciliación con el mundo" (entrevista con Carlos Cortés, Universidad. Suplemento Forja (mayo 1999); Aurelia Dobles, "El lado siniestro de Costa Rica" ("Cruz de olvido"), La Nación. Suplemento Ancora (25 de abril 1999). 
José grotesco y siniestro, donde las referencias que remiten a hechos, figuras y lugares familiares y fácilmente ubicables para el lector, solo aparecen en el texto como el residuo apenas reconocible de otro mundo, un mundo subterráneo desfigurado por el mal, la corrupción, el terror y la violencia.

Los comportamientos culturales y discursivos de la clase media y los estratos marginales se exploran en algunas novelas de Rodolfo Arias $^{26}$ y Sergio Muñoz El Emperador Tertuliano y la legión de los superlimpios (1992) de Arias juega hábilmente con un lenguaje narrativo que parodia el punto de vista y los discursos — cargados de muletillas verbales, eslóganes comerciales, dialectos populares y fórmulas burocráticas - de sus personajes, para ofrecer una visión entre humorística y patética de las aspiraciones y esperanzas, corroídas por el sistema burocrático, carcomidas por la crisis, las limitaciones y la pobreza de perspectivas, de los oficinistas y empleados públicos. La exploración de los sueños consumistas y la enajenación de la clase media se continúa en la segunda novela del mismo autor, Vamos a Panamá (1997). Los dorados (1999), ópera prima de Sergio Muñoz, explora el mundo y el lenguaje de los excluidos y marginados, sus estrategias de autoafirmación y sobrevivencia, sus esfuerzos por afirmar la dignidad, el amor o la esperanza en un mundo dominado por la miseria, cuyas únicas perspectivas parecen ser la violencia, el crimen, la droga y la prostitución.

Recursos formales “posmodernos” semejantes a los de algunos textos mencionados con anterioridad, aunque aplicados a contenidos muy diversos, alejados de toda referencia a la realidad costarricense, utilizan los relatos y novelas de Herra ${ }^{27}$, La guerra prodigiosa (1986),

26. Manuel Bermúdez, "Tragicómica idiosincracia" (Vamos para Panamá), Universidad, Suplemento Los Libros (agosto 1997); María Montero, "El lenguaje es un juego" (entrevista con Rodolfo Arias) La Nación, Suplemento Ancora (6 de julio 1997).

27. Amalia Chaverri, "Viaje al reino de los deseos: aventuras/búsquedas/géneros", Revista de Filología y Linguística de la Universidad de Costa Rica, año 19, n.1 (1993) 65-73 y "La capacidad dialógica de los intertítulos en El genio de la botella", Revista de Filología y Linguística de la Universidad de Costa Rica, año 22, n.1 (1996) 65-81; 
Elgenio de la botella (1990), Viaje al reino de los deseos (1992). Listos textos juegan profusamente con la intertextualidad y los anacronismos, las referencias a otros textos y discursos que van desde La Biblia y las mitologías clásicas a la literatura fantástica y la ciencia-ficción contemporáneas, para poner en evidencia el carácter convencional de toda representación de la realidad, incluyendo su propia escritura.

Un numeroso grupo de novelas de estos años desarrolla la temática, introducida en las décadas anteriores por Chase y Hurtado, del joven en busca de su identidad o su integración conflictiva a un mundo social que en algunos de estos textos se va tornando cada vez más ominoso, ajeno y hostil, como en los relatos y novelas de Soto (Mitomanías, 1983; L a estrate gia de la araña, 1985; La torre abolida, 1995; Dicen que los monos éramos felices, 1996) o Rivas (Esa orilla sin nadie, 1988). Predomina en estas novelas el tema de la incomunicación, la soledad y el aislamiento: los personajes deambulan en un mundo que no les ofrece asidero ni respuesta; toda relación se vuelve decepcionante, conflictiva y dolorosa, y los personajes desembocan con frecuencia en el suicidio o la muerte ${ }^{28}$.

En algunos textos de autores nacidos en la década de 1950 se hace alusión explícita a las luchas, discusiones y acontecimientos que marcaron las utopías juveniles de los 60 y 70, especialmente a las legendarias manifestaciones contra ALCOA en abril de 1970, o a las luchas revolucionarias en Nicaragua a finales de los 70 y principios de los 80. Estos relatos adquieren un formato testimonial donde se rememora - entre la nostalgia y el desencanto- el aprendizaje

Alexander Jiménez, "Sisma escritural. Acercamiento a la escritura de Rafael Angel Herra" en Alfonso de Toro, editor, Postmodernidad y postcolonialidad (Frankfurt am Mein: Vervuert, 1997) 233-253; Sonia Quesada Sánchez, Viaje al mundo de los deseos. Intertextualidad y era cibernética (tesis de maestría, Universidad de Costa Rica, 1994); Sonia Marta Mora , "La palabra ante el espejo. La novela costarricense de la década del 80 ", mimeo.

28. Margarita Rojas, "La ciudad y sus espejos", La Nación, Suplemento Ancora (27 de setiembre de 1998) 27-9 y Margarita Rojas y Flora Ovares, 100 años de literatura costarricense. 
erótico, social y político de jóvenes cuyas rupturas y rebeldías emergentes se afirman con dificultad en medio de las costumbres y valores conservadores dominantes. El erotismo juega en muchos de estos relatos un papel central, relacionado casi siempre con los proyectos de emancipación y rebelión de los protagonistas contra el orden social establecido.

Con frecuencia en estos textos las protagonistas son mujeres y su experiencia se convierte también en un estudio de las relaciones de género y una denuncia del patriarcalismo. A este grupo se adscriben obras como La huella de abril (1989) de Alicia Miranda, De qué manera te olvido (1990) de Dorelia Barahona, Historias de un testigo interior (1990) de Rosibel Morera, Los ojos del antifaz (1999) de Adriano Corrales ${ }^{29}$, Desconciertos en un jardín tropical (1999) de Magda Zavala $^{30}$. En muchas de estas novelas destaca el esfuerzo por incorporar en el texto los discursos y culturas (formas coloquiales, argots juveniles o populares, terminología académica y revolucionaria, la cultura popular y de masas) propios de la juventud universitaria y revolucionaria de los años 70 y principios de los 80 . Las relaciones de género y la temática femenina se explora intensamente también en la obra narrativa - ya mencionada - de Lobo, de Berrón (La última seducción, El expediente, 1989, La cigarra autista, 1992) y de Rossi ${ }^{31}$ (María la noche, 1985; La loca de Gandoca, 1992; Situaciones conyugales, 1993).

29. Alberto Cañas, "Chisporroteos" (Los ojos del antifaz) La República (6 de noviembre de 1999) y Guillermo Fernández Alvarez, "Viaje por un corazón militante” (Los ojos del antifaz)”, La Nación, Suplemento Ancora (15 de agosto de 1999).

30. Giovanna Giglioli, "Los hermosos desconciertos de Magda Zavala", Universidad, Suplemento Los Libros (junio 1999) y Víctor Valembois, "Novela de ruptura sobre jóvenes” (entrevista con Magda Zavala), La Nación, Suplemento Ancora (13 de junio 1999).

31. Katia Benavides Romero, "La reconstrucción de la autoimagen dañada en María !a noche”, Letras, n. 15-16-17 (1985-1986) 305-314; Rima de Vallbona, “'Maria la noche'. Erotismo, remembranzas tropicales y misterio", La Nación. Supléménio Ancora (3 de setiembre 1986); Alexandra Monturiol Méndez, De lo íntimo a lo público en "La loca de Gandoca" de Ana Crisiina Rossi (tesis, Universidad de Costa Rica, 
María la noche de Rossi recoge en una compleja novcla muchas de las preocupaciones ideológicas y estéticas de esta promoción literaria. La novela, ubicada en Londres, alterna los monólogos de dos personajes contrapuestos: Antonio, académico español, representa cl aspecto masculino, lógico y racional; Mariestela, exestudiante "tropical" costarricense, representa el aspecto femenino, vivencial y pulsional. En las relaciones entre los personajes se explora de manera novedosa el viejo problema - permanente a lo largo de la historia literaria costarricense - de la relación entre lo "propio" y lo "ajeno", lo nacional y lo cosmopolita. En el personaje de Mariestela, además, se contraponen dos ámbitos sociales y culturales: San José y el Valle Central, la Costa Rica oficial y "civilizada", se opone al Caribe, la parte oculta, vital y pulsional, de la misma forma que la familia y el orden social convencionales, se oponen a las experiencias de la juventud "hippie", transgresora y anticonvencional de los setenta. La ruptura con las represiones y tabúes sexuales, paralela a la ruptura con el discurso lógico y convencional, se corresponde en el texto con la búsqueda de un nuevo lenguaje, nuevas formas de explorar la realidad o de comunicarse consigo mismo, con la pareja y con el mundo. El discurso narrativo además varía desde la discusión casi ensayística de teorías económicas y epistemológicas, hasta la evocación casi lírica de experiencias y paisajes; al mismo tiempo, mantiene al lector en una ambigüedad constante entre diversos planos de la realidad, el presente y el pasado, lo vivido y lo evocado, el sueño, la fantasía o la alucinación. Tanto en la novela de Rossi como en relatos y novelas de Uriel Quesada y J.R. Chaves ${ }^{32}$. (Los susurros de Perseo, 1994; Paisaje con tumbas pintadas en rosa, 1998) se explora también uno de los

1994; Alicia Miranda Hevia, “La madrugada rosa" ("María la noche”), en Las sílabas azules (San José: Guayacán, 1991), 69-74; Alfredo Díaz Castro, “'La loca de Gandoca: una aproximación al paisa je y a las sensaciones”, Káñina, año 19, n. 1 (1995) 19-23.

32. Myriam Bustos Arratia, "'Paisa je con tumbas pintadas en rosa"', Universidad, Suplemento Los Libros (febrero 1999). 
temas que habían permanecido más censurados en la literatura costarricense: el de las relaciones homoeróticas, que en la última novela citada se enmarcan en el ambiente de temor, segregación e intolerancia provocado por la aparición del SIDA en los años 80 .

La tónica general de la narrativa de las décadas finales del siglo $\mathrm{XX}$ es la de una desilusión crítica con respecto a los grandes mitos fundadores de la nacionalidad: democracia, excepcionalidad, progreso, optimismo. En gran parte de estos textos la crítica se orienta hacia la burla de los mitos y discursos oficiales, los símbolos y figuras consagradas por los discursos políticos y religiosos tradicionales, mediante el uso de procedimientos como la ironía, la sátira o la parodia, el humor irreverente, las reversiones y travestimientos carnavalescos y desacralizadores.

En términos generales, en estos textos se incrementa el sentimiento de enajenación del sujeto con respecto a un mundo social que se percibe - sobre todo en los autores más jóvenes- como ajeno, ominoso u hostil, y cada vez menos como un orden inteligible o modificable. El mundo narrativo se torna grotesco o absurdo, amenazante o siniestro: adquiere los contornos de una pesadilla, un laberinto, un caos, una realidad incoherente, ajena a toda comprensión o sentido, refractaria a toda posible transformación regeneradora. La sensación de extrañeza, exilio o enajenación con respecto al mundo, se fortalece en muchos de estos textos mediante la presencia de personajes que se perciben como un ser anómalo, marginado o excluido del orden o de la normalidad, como desecho, loco, monstruo, animal o planta. De aquí el recurso frecuente en estos textos a los desdoblamientos y las metamorfosis: persona jes ena jenados que pierden su identidad, y situaciones donde se borran los límites entre ser humano, animal o vegetal ${ }^{33}$. En la narrativa de este período se continúa el proceso - perceptible desde los años 60 - de disolución de las fronteras entre las vivencias subjetivas y las experiencias objetivas, o entre "interioridad" y "exterioridad"; la

33. Margarita Rojas, "La ciudad y sus espejos". 
Icndencia a trasladar la fuente de los conflictos desde el "exterior" a la propia subjetividad del personaje ${ }^{34 *}$, con lo que se borran también las fronteras entre lo "real" y lo fantástico o imaginario.

En muchos de los autores del último tercio del siglo $\mathrm{XX}$ se percibe también un tipo de escritura que exige un nuevo tipo de lector: estos textos buscan la complicidad o la participación activa del lector en la interpretación de los signos, ya sea mediante el juego con las convenciones que determinan su propia escritura; ya sea por medio de la provocación o el desconcierto, mediante la ruptura violenta con las convenciones y protocolos del sentido común o la sindéresis; ya sea mediante la ruptura con los criterios tradicionales de verosimilitud, la combinación de diversos planos de realidad o de lo real y lo imaginario; ya sea mediante el juego con recursos como el humor, la ironía o la parodia, la mezcla de lenguajes o géneros que por su naturaleza apuntan a la ambivalencia, la incertidumbre, la duda. Todo esto traduce la sensación de enfrentarse a un mundo desarticulado y alienante o un mundo donde domina la incertidumbre, la contingencia () la banalidad, las asociaciones o combinaciones aleatorias de vivencias y objetos sin nexos sólidos o causales estables, el absurdo y el sinsentido o la represión y la violencia.

Los autores de este último tercio de siglo viven la experiencia de un mundo complejo y cambiante: desde el ascenso de los ideales revolucionarios y las utopías juveniles de los años 60 y 70, hasta la crisis de los ochenta, el "fin de las utopías", el imperio del nuevo capitalismo globalizado, la ideología neoliberal y el "posmodernismo" escéptico y desesperanzado de fines del siglo XX. De aquí que constituyan estos autores y estos textos un grupo heteróclito, complejo y cambiante, que oscila — de un autor a otro y de un texto a otro-entre cl entusiasmo y la esperanza o el escepticismo y el desencanto.

34. Rojas y Ovares, Cien años de literatura costarricense y Margarita Rojas, "La ciudad y los espejos". 